\title{
Systemic corticosteroids and transition to delirium in critically ill patients
}

\author{
AE Wolters ${ }^{1 *}$, DS Veldhuijzen ${ }^{1,2}$, IJ Zaal ${ }^{1}$, LM Peelen ${ }^{1,3}$, JW Devlin $^{4}$, D van Dijk ${ }^{1}$, AJC Slooter ${ }^{1}$ \\ From ESICM LIVES 2015 \\ Berlin, Germany. 3-7 October 2015
}

\section{Introduction}

Delirium is frequent in the critically ill and is associated with long-term morbidity [1]. Currently, the key approach for delirium in the ICU is avoidance of risk factors. Systemic corticosteroids are often used in the ICU, and regularly administered in high dosages, as increasing evidence suggests potential benefits of these medications in critically ill patients $[2,3]$. However, corticosteroids are proposed to be a risk factor delirium in patients with acute lung injury [4].

\section{Objective}

To investigate whether systemic corticosteroids increase the probability of transitioning to delirium in a mixed medical-surgical ICU population.

\section{Methods}

We conducted a prospective cohort study in a 32bed mixed medical-surgical ICU. Critically ill adults who stayed in the ICU for more than 24hours, without acute neurological disorders or other conditions hampering delirium assessment were included. Systemic corticosteroid administration was measured daily. Dosage were converted in milligrams (mg) prednisone equivalents. Daily mental status was classified as 'coma', 'delirium', or an 'awake without delirium' state using a previously described algorithm based on the CAM-ICU score [5]. The primary outcome, daily transition from an 'awake without delirium' state to 'delirium' was analyzed using a first order Markov multinomial logistic regression model, taking competing events such as discharge and death into account.

\section{Results}

A total of 1112 patients accounted for 9867 ICU days. The transition from being 'awake without delirium' to 'delirium'

University Medical Center Utrecht, Intensive Care Medicine, Utrecht, Netherlands

Full list of author information is available at the end of the article occurred 562 times (6\%). On 3483 days (35\%) systemic corticosteroids were administered, with a median dosage of 50 (interquartile range 25-75) mg prednisone equivalents. Administration of systemic corticosteroids was not significantly associated with the transition to delirium (adjusted odds ratio $1.08,95 \% \mathrm{CI} 0.89-1.32$ ). Increasing dosage on days patients received corticosteroids was not associated with an increased odds of transitioning to delirium either (adjusted odds ratio 1.00, 95\% CI 0.99-1.01, per $10 \mathrm{mg}$ increase in prednisone equivalents).

\section{Conclusions}

Our findings suggest that exposure to systemic corticosteroids is not a risk factor for the transition to delirium.

\section{Authors' details}

${ }^{1}$ University Medical Center Utrecht, Intensive Care Medicine, Utrecht, Netherlands. '2Leiden University, Institute of Psychology, Health, Medical and Neuropscyhology, Leiden, Netherlands. ${ }^{3}$ Julius Center for Health Sciences and Primary Care University Medical Center Utrecht, Department of Epidemiology, Utrecht, Netherlands. ${ }^{4}$ Northeastern University, School of Pharmacy, Bosten, United States.

\section{Published: 1 October 2015}

\section{References}

1. Reade MC, Phil D, Finfer S: Sedation and delirium in the intensive care unit. N Engl J Med 2014, 370:444-54.

2. Sprung $C$, Annane D, Keh D, et al: Hydrocortisone therapy for patients with septic shock. N Engl J Med 2008, 358:111-24.

3. Marik $P$, Meduri $G$, Rocco $P$, et al: Glucocorticoid treatment in acute lung injury and acute respiratory distress syndrome. Crit Care Clin 2011, 27:589-607.

4. Schreiber MP, Colantuoni E, Bienvenu OJ, et al: Corticosteroids and Transition to Delirium in Patients With Acute Lung Injury. Crit Care Med 2014, 42:1480-6.

5. Zaal IJ, Tekatli H, van der Kooi AW, et al: Classification of daily mental status in critically ill patients for research purposes. J Crit Care 2015, 30:375-80.

doi:10.1186/2197-425X-3-S1-A30

Cite this article as: Wolters et al:: Systemic corticosteroids and transition to delirium in critically ill patients. Intensive Care Medicine Experimental 2015 3(Suppl 1):A30. (c) 2015 Wolters et al.; This is an Open Access article distributed under the terms of the Creative Commons Attribution License (http:// creativecommons.org/licenses/by/4.0), which permits unrestricted use, distribution, and reproduction in any medium, provided the original work is properly cited. 